\title{
The production of singular- and plural-dominant nouns in Dutch
}

\author{
Elisabeth Beyersmann ${ }^{\mathrm{a} *}$, Eleanor M. Dutton ${ }^{\mathrm{b}}$, Sohaila Amer ${ }^{\mathrm{b}}$, Niels O. Schiller ${ }^{\mathrm{b}}$ and Britta Biedermann ${ }^{\mathrm{c}, \mathrm{d}}$ \\ ${ }^{a}$ Laboratoire de Psychologie Cognitive, Aix-Marseille Université, Marseille, France; ${ }^{b}$ Faculty of Humanities, Leiden Institute for Brain \\ and Cognition (LIBC), Leiden University Centre for Linguistics (LUCL), Leiden, The Netherlands; ${ }^{c} A R C$ Centre of Excellence in \\ Cognition and Its Disorders, Sydney, NSW, Australia; ${ }^{d}$ Department of Cognitive Sciences, Macquarie University, Sydney, NSW, Australia
}

(Received 5 March 2014; accepted 27 February 2015)

\begin{abstract}
The role of number dominance (singular vs. plural) in word production has revealed contrasting results in Dutch and English. Here, we compared the production of Dutch regular plural forms that are more frequent than their stems (pluraldominant plurals) to plurals that are less frequent than their stems (singular-dominant plurals) in a spoken picture-naming paradigm. Moreover, the role of inflectional entropy during spoken word production was assessed. The results revealed that singular-dominant singulars were produced significantly faster and more accurately than their corresponding plurals, independently of inflectional entropy. However, the production of plural-dominant plurals and singulars was modulated by inflectional entropy, and a plural disadvantage only found if the inflectional variants were not uniformly distributed. Critically, uniformly distributed variants showed a plural advantage in this condition. Our findings suggest that singulardominant and plural-dominant plurals are processed differently, which we discuss in the context of morphological processing theories in spoken language production.
\end{abstract}

Keywords: plural dominance; morphological processing; inflectional entropy; word production; spoken picture naming

Morphological processing has gained great interest in psycholinguistic research over the past decades. Claims have been made regarding the role of distributional properties of language, showing that morphological processing is influenced by variables such as word frequency (Taft, 1979), morphological family size (Bertram, Baayen, \& Schreuder, 2000; De Jong, Schreuder, \& Baayen, 2000), spelling-meaning consistency (Chateau, Knudsen, \& Jared, 2002), affix frequency (Wurm, 1997), affix productivity, and affixal homonymy (Bertram, Schreuder, \& Baayen, 2000). Of particular interest have been stem-frequency effects, demonstrating that the morphemic stem is involved in the processing of whole words (Baayen, Dijkstra, \& Schreuder, 1997; Burani \& Caramazza, 1987; Colé, Beauvillain, \& Segui, 1989; Taft, 1979, 2004). Such evidence has been taken to suggest that not only the whole word but also its morphemic subunits play a role during word-form processing.

More recently, the exploration of word-form and stemfrequency effects have been complemented by studies examining the relative frequency between the whole word and its stem. Data from visual word recognition demonstrate that the morphological processing system is dependent on whether a morphologically complex word occurs more frequently than its stem or vice versa (Bertram, Schreuder, et al., 2000; Burani \& Laudanna, 1992; Hay, 2001). A particularly influential body of evidence stems from word recognition studies investigating the relative frequency of plurals and their corresponding singulars (Baayen, Dijkstra, et al., 1997). Plurals that are more frequent than their singulars ("plural-dominant" plurals) and plurals that are less frequent than their singulars ("singular-dominant" plurals) have constituted the key contrast of interest. Across different languages, it has been coherently shown that while there is a singular advantage for singular-dominant pairs, plural-dominant plurals and singulars do not differ (Italian: Baayen, Burani, \& Schreuder, 1997; Dutch: Baayen, Dijkstra, et al., 1997; Dutch: Baayen, McQueen, Dijkstra, \& Schreuder, 2003; French and English: New, Brysbaert, Segui, Ferrand, \& Rastle, 2004).

These findings are consistent with parallel dual route models, suggesting that whole words and morphemes can be processed simultaneously (Baayen \& Schreuder, 1999; Beyersmann, Coltheart, \& Castles, 2012). It has been proposed that morphologically complex words which are more frequent than their stem morphemes (such as pluraldominant plurals) are more likely to be processed holistically, whereas complex words which are less frequent than their stems (such as singular-dominant plurals) are more likely to be processed decompositionally (Bertram, Schreuder, et al., 2000; Burani \& Laudanna, 1992; Hay, 2001; Laudanna \& Burani, 1995). This approach predicts higher morphological processing costs for singular-dominant plurals, leading to a plural-processing disadvantage in the singular-dominant condition. Frequency does not 
present a processing bias in this condition because the processing of plurals and singulars is based on the activation of the same stem. Conversely, plural-dominant plurals are more likely to be processed as wholes; therefore, morphological processing costs should not arise, or at least to a lesser extent. Moreover, frequency does not present a processing bias because processing speed and accuracy of singulars depends on cumulative stem frequency (i.e. the summed frequencies of the singular and plural form), while processing speed and accuracy of plurals depends on surface frequency (i.e. the frequency of the plural form), which is, by definition, similar to the cumulative stem frequency of its corresponding singular. Taken together, parallel dual route models predict a processing advantage for singular-dominant but not plural-dominant singulars, which is consistent with the results reported above.

Despite the coherent pattern of findings from word recognition, the evidence from word production is less conclusive. A recent spoken picture-naming study in English replicated the pattern previously observed in word recognition, showing that while singular-dominant singulars were named faster and more accurately than their plurals, there was no difference between pluraldominant singulars and plurals (Biedermann, Beyersmann, Mason, \& Nickels, 2013). However, a Dutch picturenaming study revealed a contrasting pattern of results (Baayen, Levelt, Schreuder, \& Ernestus, 2008). Plurals were produced overall slower than singulars, suggesting that all plural forms are processed decompositionally, independently of dominance. Moreover, plural-dominant singulars and plurals were produced more slowly than singular-dominant singulars and plurals, which was argued to be due to differences in selection competition between higher-level lexical-syntactic and lexicalconceptual representations (see also Levelt, Roelofs, \& Meyer, 1999). Interestingly, the authors reported effects of inflectional and relative inflectional entropy, suggesting that the paradigmatic organisation of inflected forms in the mental lexicon plays a fundamental role both at the level of individual lexemes and at the general level of the class of nouns (for related evidence from speech production, see also Bien, Baayen, \& Levelt, 2011; Tabak, Schreuder, \& Baayen, 2010).

One possible explanation for the diverging findings between the English and the Dutch data is that morphological structure in English and Dutch evokes fundamentally different processing mechanisms. For instance, the majority of English plurals are constructed with a regular suffix $(-s)$. In Dutch, however, two regular plural morphemes ( $-s$ and $-e n)$ exist, with -en being a slightly longer orthographic unit. Also, the addition of the more frequent Dutch regular plural (-en) changes syllabic word structure (bloem vs. bloemen), which is not the case in English (cat vs. cats; although exceptions exist: horse vs. horses).
These factors indicate that Dutch plural morphemes are orthographically and phonologically more conspicuous. It is therefore possible that Dutch plural suffixes are activated more readily and are therefore more prone to morphological processing costs, which might explain why there was an overall plural-processing disadvantage in the Dutch but not in the English study.

The aim of our study was to address the controversial evidence from English and Dutch spoken word production and test whether or not the production of plural- and singular-dominant words differs in a group of Dutch participants. The exploration of plurals in Dutch is particularly revealing, as they are regular and productive and expected to be subject to rapid, automatic morphological processing (Bertram, Schreuder, et al., 2000). We copied Biedermann et al.'s (2013) design but introduced two important extensions. We used two plural suffixes (-en and $-s$ ), rather than one $(-s)$, aiming at inducing an additional challenge to the morphological system. Also, just like Baayen, Davidson, and Bates (2008), one of the plural suffixes we used (i.e. -en) was able to change the syllabic structure of the stem. In order to rule out that any effects were due to differences in word frequencies, we selected our materials such that plural-dominant plurals and singular-dominant plurals were matched on cumulative stem frequency and surface frequency. If it is true that the same morphological processing mechanisms apply to all plurals, regardless of dominance (Baayen et al., 2008), we would expect an overall processing disadvantage for plurals compared to singulars due to morphological processing costs. If however, as previously argued by Biedermann and colleagues (2013), the processing mechanisms underlying singular-dominant and plural-dominant word production are fundamentally different (see Discussion for a more detailed theoretical perspective), we would expect a processing advantage for singular-dominant singulars compared to their corresponding plurals. No difference should arise between pluraldominant singulars and plurals. Second, in order to explore whether or not the distributional probabilities of inflected forms play a role during spoken plural production, inflectional entropy and relative inflectional entropy measures were included in the analyses reported below.

\section{Method \\ Participants}

Forty-four students from Leiden University participated in this study. All participants had normal or corrected-tonormal vision and were native Dutch speakers.

\section{Materials}

Materials were created following the selection criteria in Biedermann et al. (2013). We selected 80 targets, which 
Table 1. Mean item characteristics.

\begin{tabular}{lcc}
\hline \multicolumn{1}{c}{ Property } & Plural-dominant & Singular-dominant \\
\hline Plural & & \\
Word frequency & $21.7(28.6)$ & $9.8(12.3)$ \\
Stem frequency & $57.8(108.6)$ & $61.4(76.5)$ \\
Phonological N & $7.9(6.2)$ & $8.4(5.5)$ \\
Orthographic N & $10.7(8.9)$ & $12.0(6.7)$ \\
Number of syllables & $2.2(0.5)$ & $2.0(0.0)$ \\
Number of phonemes & $5.1(1.4)$ & $4.8(1.02)$ \\
Number of letters & $6.3(1.1)$ & $6.3(0.7)$ \\
Age of acquisition & $3.4(1.8)$ & $3.8(1.8)$ \\
Visual complexity & $2.3(0.6)$ & $2.4(0.5)$ \\
Name agreement & $1.0(0.04)$ & $1.0(0.04)$ \\
& & \\
Singular & $9.1(12.9)$ & $48.7(69.3)$ \\
Word frequency & $57.8(108.6)$ & $61.4(76.5)$ \\
Stem frequency & $9.9(7.7)$ & $10.4(7.1)$ \\
Phonological N & $11.2(9.4)$ & $14.3(9.0)$ \\
Orthographic N & $1.5(0.6)$ & $1.2(0.4)$ \\
Number of syllables & $4.1(1.5)$ & $3.8(1.0)$ \\
Number of phonemes & $4.8(1.4)$ & $4.3(1.1)$ \\
Number of letters & $3.1(1.5)$ & $3.3(1.5)$ \\
Age of acquisition & $2.6(0.9)$ & $2.8(0.9)$ \\
Visual complexity & $1.0(0.05)$ & $1.0(0.05)$ \\
Name agreement & & \\
&
\end{tabular}

$\mathrm{N}=$ neighbourhood. Note: Standard deviations are shown in parentheses.

were subdivided into 40 plural-dominant and 40 singulardominant words. Each subset consisted of 20 singular and 20 plural forms (Appendix 1). Both regular Dutch pluralsuffixes were used: $-s$ (tijger-s "tigers") and -en (worm-en "worms"). Plural-dominant plurals were more frequent than their singulars $(t=8.44, p<.001)$, and singulardominant singulars were more frequent than their plurals $(t=6.26, p<.001)$, with a minimum difference of 0.14 logarithmic word frequency retrieved from CELEX (Baayen, Piepenbrock, \& van Rijn, 1993; see Table 1 for item characteristics). An example of a singular-dominant and a plural-dominant picture pair is provided in Figure 1.

Target words were common nouns, selected from CELEX (Baayen et al., 1993). For each target, a picture was selected. Pictures were colour photographs representing single or multiple exemplars. For all pictures, we collected name agreement, visual complexity, and age of acquisition ratings from 20 native Dutch speakers (Table 1). Visual complexity ratings were based on a 15 point scale, with increasing number indicating increased complexity. Age of acquisition ratings were based on a 17 point scale, with increasing number indicating increased acquisition age. Pictures were named with at least $85 \%$ accuracy.

The two lists of plurals (plural-dominant vs. singulardominant) were matched on surface frequency and logarithmic cumulative stem frequency. Moreover, plurals (plural-dominant vs. singular-dominant) and singulars (plural-dominant vs. singular-dominant) were matched on phonological neighbourhood (phonological N), orthographic neighbourhood (orthographic $\mathrm{N}$ ), syllable number, phoneme number, number of letters, name agreement, visual complexity, and age of acquisition (see Table 1). To avoid item repetition, we created two counterbalanced lists.

\section{Procedure}

The procedure was adapted from Biedermann et al. (2013). Stimuli were presented centrally on-screen using DMDX (Forster \& Forster, 2003). Each trial consisted of a $200 \mathrm{~ms}$ fixation cross, followed by a blank screen for 600 $\mathrm{ms}$, which was then followed by the target picture. Targets were presented in randomised order on a black background for a maximum of 3 seconds. Between trials, a blank screen was presented for $1500 \mathrm{~ms}$. Participants were instructed to respond as quickly and accurately as possible. Responses were recorded with a free-standing (Sennheiser MKH416T condenser-type) microphone. The amplifier, Quad-Capture Roland UA-55, was configured individually for each participant.

\section{Results}

Accuracy and response times of vocal responses were corrected using CheckVocal (Protopapas, 2007). We removed data from four participants and two items (helm/helmen, vinger/vingers) because error rates (ER\%) were above $30 \%$. Incorrect responses (7.2\%) and responses below $250 \mathrm{~ms}$ or above $2000 \mathrm{~ms}$ (1.2\%) were
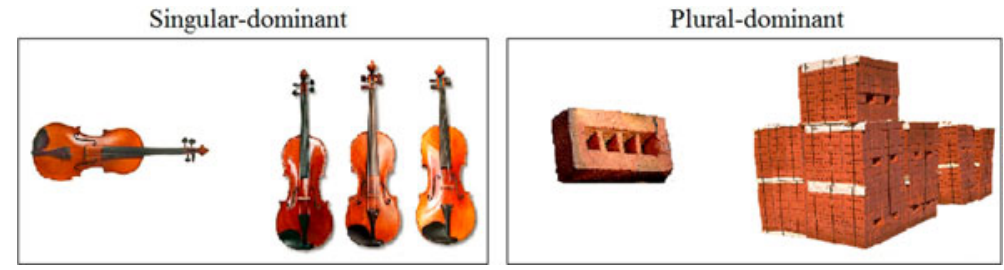

Figure 1. Example of pictures used in singular-dominant and plural-dominant conditions. 
Table 2. Mean RTs and ER\%.

\begin{tabular}{lccllc}
\hline & \multicolumn{2}{c}{ RTs } & & \multicolumn{2}{c}{ ER\% } \\
\cline { 2 - 3 } \cline { 5 - 6 } & Singular & Plural & & Singular & Plural \\
\hline $\begin{array}{c}\text { Singular- } \\
\text { dominant } \\
\begin{array}{c}\text { Plural- } \\
\text { dominant }\end{array}\end{array}$ & $936(141)$ & $1053(172)$ & $2.9(5.3)$ & $10.8(14.4)$ \\
\hline
\end{tabular}

Note: Standard deviations are presented in parenthesis.

removed from reaction time (RT) analyses. RTs and ER\% were analysed for each participant (Table 2).

Linear mixed-effects modelling was employed to perform the main analyses (Baayen, 2008; Baayen, Davidson, \& Bates, 2008). RTs were logarithmically transformed. Fixed and random effects were only included if they significantly improved the model's fit in a backward stepwise model selection procedure. Models were selected using chi-squared log-likelihood ratio tests with regular maximum likelihood parameter estimation. Trial order was included to control for longitudinal task effects such as fatigue or habituation. In order to avoid dichotomising a numerical predictor, the factor Dominance was included as a continuous variable (log[frequency_singular] - $\log [$ frequency_plural $])$. Given that seven item pairs included stem-final voicing alternations (e.g. naald/naalden), but only one of the seven pairs was plural-dominant, we included this factor as a covariate in the model. For each item, inflectional and relative inflectional entropy values were calculated (following Baayen et al., 2008) and included as fixed effects in the analyses. Relative inflectional entropy was measured based on the probability distribution of all Dutch singular and plural nouns $(0.748$, 0.252; Baayen et al., 2008).

A linear mixed-effects model as implemented in the lme4 package (Bates, Maechler, Bolker, \& Walker, 2014) in the statistical software R (Version 3.0.3; R Development Core Team, 2008) was created with seven fixed effect factors (number: singular, plural; dominance; inflectional entropy; relative inflectional entropy; stem-final voicing alternations; jpeg-size; trial order), their interactions, and two random effect factors (random intercepts for participants and items). The lmer default coding for treatment contrasts was used (i.e. reference level "plural" for factor number). $P$-values were determined using the package lmerTest (Kuznetsova, Brockhoff, \& Christensen, 2014). Trial order, voicing alternations, jpeg-size, and relative inflectional entropy ${ }^{1}$ did not improve the model's fit and were excluded. A detailed summary of the final model specifying random and fixed effects is reported in Appendix 2. RT analyses revealed a significant three-way interaction between number, dominance, and inflectional entropy $(t=3.50, p<.001)$ and a significant interaction between dominance and number $(t=2.11, p=.035)$.
Moreover, we observed a significant interaction between number and inflectional entropy $(t=3.23, p<.001)$, indicating that the number effect was larger for items with low inflectional entropy values. There was also a significant effect of number $(t=3.15, p=.002)$.

The error analyses were performed based on the same principles as the RT analyses. We applied a binomial variance assumption to the trial-level binary data using the function glmer as part of the R-package lme4. Inflectional entropy and relative inflectional entropy did not improve the model's fit and were therefore excluded from the analyses. There was a significant interaction between number and dominance $(t=2.26, p=.024)$ and a significant effect of number $(t=2.36, p=.018)$. No other effects were significant.

\section{Discussion}

The purpose of our study was to explore the role of relative frequency between singulars and plurals in morphological processing during spoken word production. We examined singular-dominant and plural-dominant plurals in Dutch participants and found a clear-cut pattern of results. Our data unambiguously showed a processing advantage for singular-dominant singulars compared to their plurals, which was reflected in both RT and error data, independently of inflectional entropy. Critically, although no such difference was found between pluraldominant singulars and their plurals, a singular advantage did indeed emerge (which is consistent with Baayen, Levelt, et al., 2008), but only for items with nonuniformly distributed inflectional variants (see Figure 2). Uniformly distributed variants showed a trend to a pluraladvantage in this condition. Our findings suggest that the distributional probabilities of the individual inflected forms play a role, particularly during the spoken production of plural-dominant words. Importantly, the interaction between number and dominance persisted, even when inflectional entropy (or relative inflectional entropy) was included in the model, showing that this key result is not simply due to a confound with the lexeme's distributional properties.

Our findings are in line with previous findings from spoken word production (Biedermann et al., 2013) and word recognition (Baayen, Burani, et al., 1997; Baayen, Dijkstra, et al., 1997; Baayen et al., 2003; New et al., 2004), suggesting that the production of morphologically complex words is biased depending on the relative frequency between the whole word and its stem morpheme. These results are inconsistent with the morphological processing component of Levelt et al.'s (1999) spoken word production theory, proposing that singular-dominant and plural-dominant plurals differ at the lexical-conceptual and lexical-syntactic level (Figure 3, Panel A). Singulardominant singulars and plurals share the same lexical- 
Plural-dominant condition

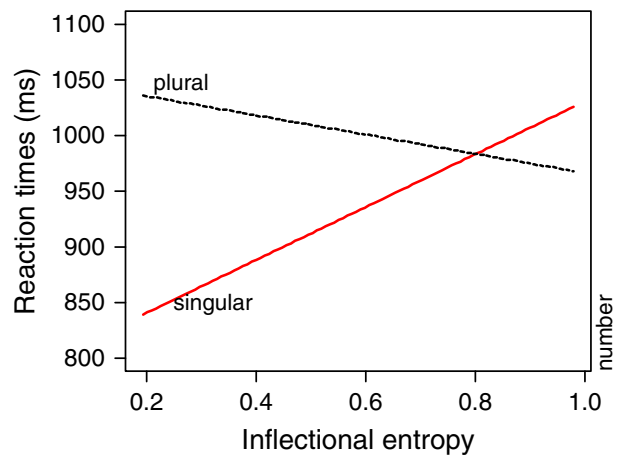

Singular-dominant condition

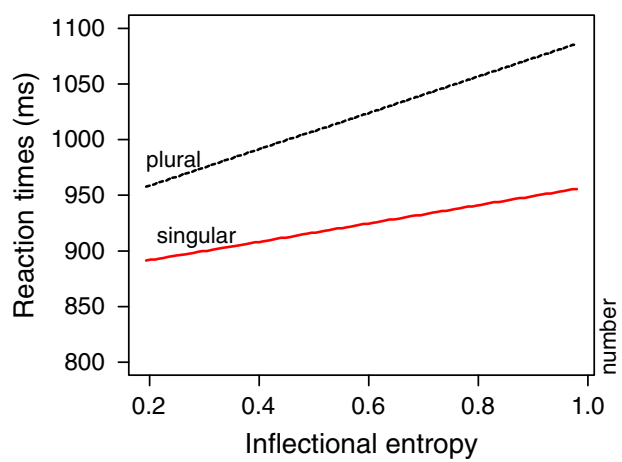

Figure 2. Influences of inflectional entropy on the effect of number, as observed in the plural-dominant (left panel) and singulardominant conditions (right panel).

concept and lexical-syntactic node, whereas pluraldominant singulars and plurals are represented independently. The double listing of plural-dominant words predicts that selection competition arises at these levels between singulars and plurals, which is not the case for singular-dominant words. Hence, plural-dominant words should be produced slower than singular-dominant words, which is inconsistent with our present findings. A further challenge for this theory is the lack of difference between uniformly distributed plural-dominant singulars and plurals. It is predicted that the production of any plural form is always obligatorily mediated by the mapping onto the word's morphemic subunits. That is, morphological processing costs should arise for all plurals, independently of dominance.

Our findings appear to be more in line with two recent proposals that explicitly address word production constraints related to singular- and plural-dominance. The first proposal is one by Biedermann and colleagues (2013), suggesting that morphologically complex words can be processed as whole word-form units or decompositionally during spoken word production (Figure 3, Panel B). The authors argue, unlike Levelt et al. (1999), that differences between the representation of singular- and pluraldominant nouns at lexical-conceptual and lexical-syntactic-level are not necessary. Instead, the difference between plural-dominant and singular-dominant plurals is implemented entirely at the phonological word-form level. Singular-dominant plurals are processed decompositionally $($ stem $+s)$, whereas plural-dominant items are processed as full forms at this level.

Consistent with the effects in the singular-dominant conditions, this proposal predicts that words that are less frequent than their stems (tigers) are more likely to be decomposed. The spoken word production system will activate the higher frequent stem (tiger) more rapidly, thus leading to the production of the spoken output. Hence, the production speed of tigers is, like tiger, influenced by the frequency of its stem. Critically, however, morphological processing costs arise via the decompositional route, which explains why the plural is produced more slowly and less accurately than its singular. Moreover, the proposal predicts that words that are more frequent than their morphemic subunits (fingers) are more likely to be processed as whole units. The whole word form is activated more rapidly, leading to the production of the spoken output. No morphological processing costs arise via the whole word route. Furthermore, since by definition each occurrence of any plural automatically boosts the frequency of its corresponding singular, speed and accuracy of plural-dominant singular and plurals should not differ during spoken word production. However, this prediction is only partially consistent with our findings, because, as our present data indicate, plural-dominant singulars and plurals do indeed differ as a function of inflectional entropy. Thus, this second account does not entirely withstand the present data.

A proposal that may be more successful in accounting for our data is one by Nickels, Biedermann, Fieder, and Schiller (2014). It returns to the original idea of a double listing for singulars and plurals at lexical-syntactic level (as proposed by Levelt et al. 1999), but with the important difference that double listing is assumed for all singulars and plurals, regardless of dominance. The authors propose a spoken word production model with three different processing levels, comprising a lexical-conceptual, a lexical-syntactic, and a phonological word-form level (Figure 3, Panel C). At the lexical-conceptual level, plural nouns such as tigers are represented as one node for tiger and the feature "multiple", which are both mapped onto the lexical-syntactic representation of tigers. The lexicalsyntactic level holds two entries, one for the singular and one for the plural, which in turn activate the corresponding phonological word-form representations of stem (tiger) and suffix $(-s)$. Critically, Nickels et al. argue that differences in processing singular- and plural-dominant plurals are based on different weightings in connections between the lexical-conceptual and lexical-syntactic level. 


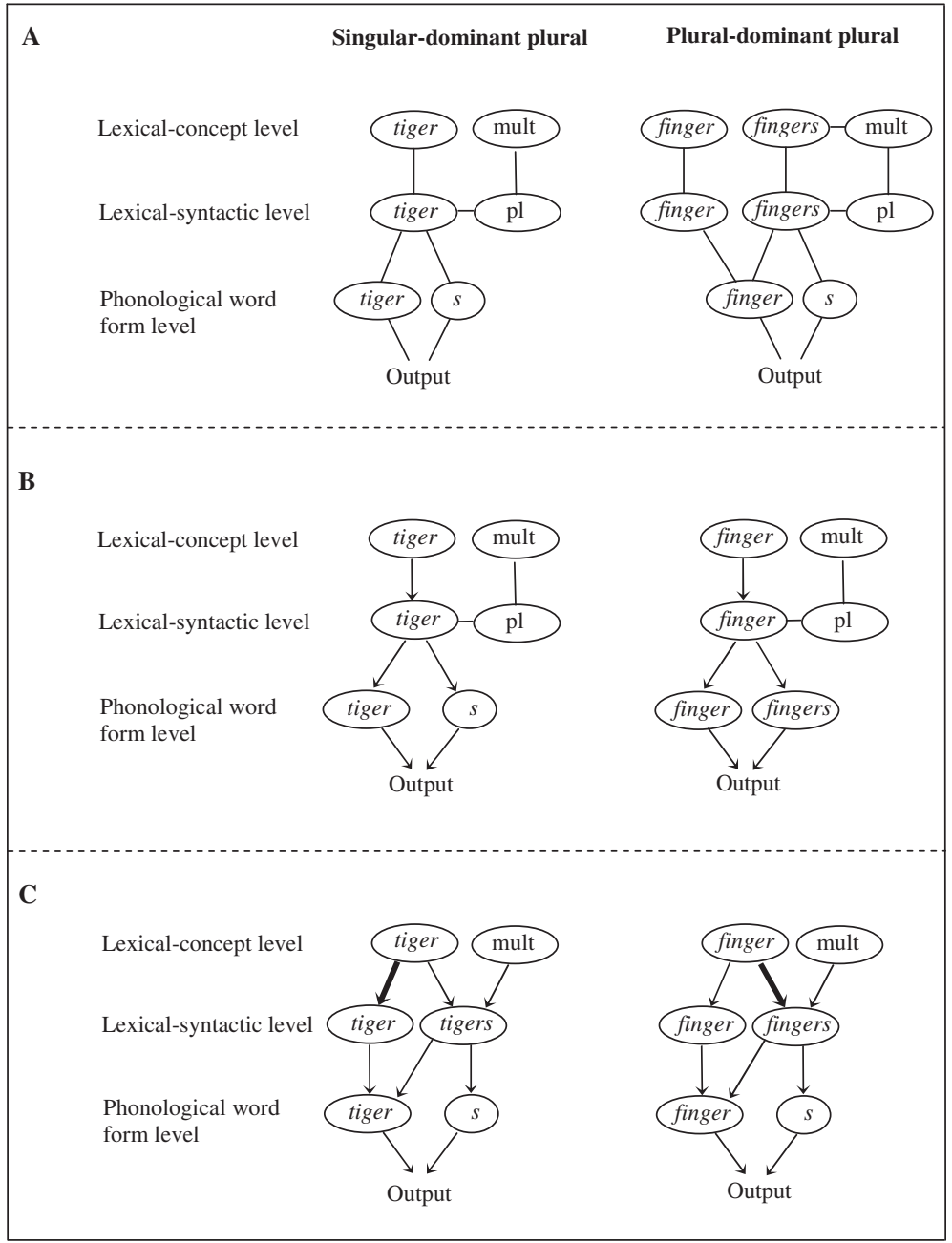

Figure 3. Panel A represents the production of singular-dominant and plural-dominant plurals, based on a word production theory proposed by Levelt et al. (1999). Panel B refers to a morphological processing theory of word production proposed by Biedermann et al. (2013), and Panel C refers to a theory by Nickels et al. (2014).

This proposal thus diverges from Levelt et al.'s (1999) strong assumption that full-form relative to decompositional storage at these levels is what differentiates between singular- and plural-dominance.

Consistent with the singular-dominant effect, Nickels et al.'s (2014) proposal predicts that the lexical-concept representation of the plural (tigers) spreads activation to the lexical-syntactic representations of singular (tiger) and plural (tigers). Importantly, the singular is activated more strongly, thus creating a processing benefit for singulars compared to plurals. The lexical-syntactic representations of tiger and tigers then spread activation to decomposed word-form representations of tiger $+s$. Hence, morphological processing costs arise due to decomposition into stem and suffix, which further explains why plurals are produced more slowly and less accurately than singulars. Moreover, consistent with the results in the pluraldominant conditions, the proposal predicts that the lexical-concept representation of the plural (fingers) spreads activation to the lexical-syntactic representations of singular (finger) and plural (fingers). Despite the stronger link between lexical-conceptual and lexical-syntactic representations of the plural, morphological processing costs arise due to decomposition of the plural at the word-form level, which cancel out the frequency advantage. Most critically, this theory can account for the finding that the plural production system is affected by the lexeme's probability distribution, as evidenced by the significant three-way interaction between dominance, number, and inflectional entropy. Our present data suggest that the flexible weightings of links between lexicalconcept nodes and lexical-syntactic nodes are not only biased as a function of plural-dominance but also subject to differences in inflectional entropy.

One explanation for the vulnerability of pluraldominant words may be that Dutch singulars typically 
occur more frequently than Dutch plurals and not vice versa (which is likely to be the case in most IndoEuropean languages), as evidenced by the probability distribution of the inflectional class $(\mathrm{Q}=$ probability distribution of all singular and plural nouns in Dutch $=$ 0.748, 0.252; Baayen, Levelt, et al., 2008). Plural-dominant plurals that are uniformly distributed only moderately violate this expectation. Therefore, the production system continues to benefit from the plural's frequency advantage during morphological processing. However, as inflectional entropy drops, plural-dominant plurals begin to increasingly violate this expectation, which adds to the processing costs of the production system (see Figure 2, left panel). Here, the production system appears to fall back on a more time-costly processing procedure, which carefully verifies the correctness of the target word, taking into account its morphological constituents, thus leading to a plural processing disadvantage.

Questions remain regarding the inconsistencies between our Dutch data and the Dutch results reported by Baayen and colleagues (2008). Similar to Baayen et al. (2008), we used suffixes that partly changed the syllabic structure of the plural. It therefore seems unlikely that the syllabic change in plural form is the source for the deviating findings. Moreover, since all our participants were Dutch native speakers, we can rule out the earlier hypothesis (Biedermann et al., 2013) that the controversy might be due to language-specific differences in morphological structure at phonological word-form level. One possibility for the observed differences might be that our items were selected from a picture set with at least $85 \%$ name agreement, whereas Baayen et al. (2008) only used a familiarisation phase. Given that it may be harder to achieve high name agreement values for pictures representing multiple objects than pictures presenting individual objects, it is possible that name agreement was lower for plurals than singulars in Baayen et al. (2008), which would explain why plurals were responded to more slowly than singulars. However, the most likely explanation for the absence of a dominance-by-number interaction in Baayen and colleagues' Dutch findings (2008) may be that the mean inflectional entropy of the selected pluraldominant words was lower (mean $=0.606$ ) than of the ones selected here $($ mean $=0.820)$. In line with this hypothesis, our present findings demonstrate that this key interaction disappears for plural-dominant words with low inflectional entropy. Hence, our data provide an important link between the results from previous production studies (Baayen, Levelt, et al., 2008; Biedermann et al., 2013), suggesting that inflectional entropy is a key factor modulating the production of plural-dominant plurals.

Taken together, there is now converging evidence from spoken word production (Biedermann et al., 2013; for evidence from aphasia, see Biedermann, Lorenz, Beyersmann, \& Nickels, 2012; Luzzatti, Mondini, \& Semenza,
2001) and word recognition (Baayen, Burani, et al., 1997; Baayen, Dijkstra, et al., 1997; Baayen et al., 2003; New et al., 2004), showing that the morphological processing system is biased depending on whether the complex word form is more frequent than its stem or vice versa. Our data demonstrate that singular-dominant plurals are produced slower and less accurately than their stems (independently of inflectional entropy), whereas the production of pluraldominant singulars and plurals is modulated by inflectional entropy. While a singular advantage only arises in a context in which the inflectional variants are non-uniformly distributed, uniformly distributed variants show a plural-advantage in this condition. These results challenge earlier proposals of plural production (e.g., Levelt et al., 1999) and demonstrate that recently revised theories of spoken word production are necessary to account for the fundamentally different mechanisms underlying the production of singular-dominant and plural-dominant words (e.g., Biedermann et al., 2013; Nickels et al., 2014).

\section{Acknowledgment}

We thank Xavier Alario for helpful comments and suggestions.

\section{Disclosure statement}

No potential conflict of interest was reported by the authors.

\section{Funding}

This project was supported by a postdoctoral grant from the Fyssen Foundation to Elisabeth Beyersmann. Britta Biedermann was funded by an Australian Research Council (ARC), Australian Postdoctoral Fellowship (APD, DP110100799).

\section{Note}

1. Relative inflectional entropy and inflectional entropy were highly correlated $(r=.974)$. When inflectional entropy was excluded, but relative inflectional entropy included within linear mixed-effects modelling, we obtained effects that were comparable to those of inflectional entropy. Therefore, we will confine the results to inflectional entropy only.

\section{References}

Baayen, R. H. (2008). Analyzing linguistic data: A practical introduction to statistics using $R$. Cambridge: Cambridge University Press.

Baayen, R. H., Burani, C., \& Schreuder, R. (1997). Effects of semantic markedness in the processing of regular nominal singulars and plurals in Italian. In G. E. B. J. V. Marle (Ed.), Yearbook of morphology 1996 (pp. 13-34). Dordrecht: Kluwer.

Baayen, R. H., Davidson, D. J., \& Bates, D. M. (2008). Mixedeffects modeling with crossed random effects for subjects and items. Journal of Memory and Language, 59, 390-412. doi:10.1016/j.jml.2007.12.005

Baayen, R. H., Dijkstra, T., \& Schreuder, R. (1997). Singulars and plurals in Dutch: Evidence for a parallel dual-route model. Journal of Memory and Language, 37(1), 94-117. doi:10.1006/jmla.1997.2509 
Baayen, R. H., Levelt, W. J. M., Schreuder, R., \& Ernestus, M. (2008). Paradigmatic structure in speech production. Chicago Linguistics Society, 43(1), 1-29.

Baayen, R. H., McQueen, J., Dijkstra, T., \& Schreuder, R. (2003). Frequency effects in regular inflectional morphology: Revisiting Dutch plurals. In R. H. Baayen \& R. Schreuder (Eds.), Morphological structure in language processing (pp. 355-390). Berlin: Mouton de Gruyter.

Baayen, R. H., Piepenbrock, R., \& van Rijn, H. (1993). The CELEX lexical database (CD-ROM). Philadelphia, PA: Linguistic Data Consortium, University of Pennsylvania.

Baayen, R. H., \& Schreuder, R. (1999). War and peace: Morphemes and full forms in a noninteractive activation parallel dual-route model. [Article]. Brain and Language, 68(1-2), 27-32. doi:10.1006/brln.1999.2069

Bates, D., Maechler, M., Bolker, B., \& Walker, S. (2014). lme4: Linear mixed-effects models using Eigen and S4. R package version 1.1-5. Retrieved from http://CRAN.R-project.org/ package $=1 \mathrm{me} 4$

Bertram, R., Baayen, R. H., \& Schreuder, R. (2000). Effects of family size for complex words. Journal of Memory \& Language, 42, 390-405. doi:10.1006/jmla.1999.2681

Bertram, R., Schreuder, R., \& Baayen, R. H. (2000). The balance of storage and computation in morphological processing: The role of word formation type, affixal homonymy, and productivity. Journal of Experimental Psychology: Learning, Memory, \& Cognition, 26, 489-511. doi:10.1037/02787393.26.2.489

Beyersmann, E., Coltheart, M., \& Castles, A. (2012). Parallel processing of whole-words and morphemes in visual word recognition. The Quarterly Journal of Experimental Psychology, 65, 1798-1819. doi:10.1080/17470218.2012.672437

Biedermann, B., Beyersmann, E., Mason, C., \& Nickels, L. (2013). Does plural dominance play a role in spoken picture naming? A comparison of unimpaired and impaired speakers. Journal of Neurolinguistics, 26, 712-736. doi:10.1016/j. jneuroling.2013.05.001

Biedermann, B., Lorenz, A., Beyersmann, E., \& Nickels, L. (2012). The influence of plural dominance in aphasic word production. Aphasiology, 26, 985-1004. doi:10.1080/026870 38.2012.660459

Bien, H., Baayen, R. H., \& Levelt, W. J. M. (2011). Frequency effects in the production of Dutch deverbal adjectives and inflected verbs. Language and Cognitive Processes, 26, 683715. doi:10.1080/01690965.2010.511475

Burani, C., \& Caramazza, A. (1987). Representation and processing of derived words. Language and Cognitive Processes, 2, 217-227. doi:10.1080/01690968708406932

Burani, C., \& Laudanna, A. (1992). Units of representation for derived words in the lexicon. In R. Frost \& L. Katz (Eds.), Orthography, phonology, morphology and meaning (pp. 361-376). Amsterdam: Elsevier Science.

Chateau, D., Knudsen, E. V., \& Jared, D. (2002). Masked priming of prefixes and the influence of spelling-meaning consistency. Brain and Language, 81, 587-600. doi:10.1006/ brln.2001.2549

Colé, P., Beauvillain, C., \& Segui, J. (1989). On the representation and processing of prefixed and suffixed derived words:
A differential frequency effect. Journal of Memory and Language, 28, 1-13.

De Jong, N. H., Schreuder, R., \& Baayen, R. H. (2000). The morphological family size effect and morphology. Language and Cognitive Processes, 15, 329-365. doi:10.1080/016909 60050119625

Forster, K. I., \& Forster, J. C. (2003). DMDX: A Windows display program with millisecond accuracy. Behavior Research Methods, Instruments, \& Computers, 35(1), 116124. doi:10.3758/BF03195503

Hay, J. (2001). Lexical frequency in morphology: Is everything relative? Linguistics, 39, 1041-1070. doi:10.1515/ling.2001. 041

Kuznetsova, A., Brockhoff, P. B., \& Christensen, R. H. B. (2014). ImerTest: Tests for random and fixed effects for linear mixed effect models (lmer objects of lme4 package): $\mathrm{R}$ package version 2.0-6. Retrieved from http://CRAN.R-project.org $/$ package $=$ lmerTest

Laudanna, A., \& Burani, C. (1995). Distributional properties of derivational affixes: Implications for processing. In L. B. Feldman (Ed.), Morphological Aspects of Language Processing: Cross-Linguistic Perspectives (pp. 345-364). Hillsdale: Erlbaum.

Levelt, W. J. M., Roelofs, A., \& Meyer, A. S. (1999). A theory of lexical access in speech production. Behavioral and Brain Sciences, 22, 1-75.

Luzzatti, C., Mondini, S., \& Semenza, C. (2001). Lexical representation and processing of morphologically complex words: Evidence from the reading performance of an Italian agrammatic patient. Brain and Language, 79, 345-359. doi:10.1006/brln.2001.2475

New, B., Brysbaert, M., Segui, J., Ferrand, L., \& Rastle, K. (2004). The processing of singular and plural nouns in French and English. Journal of Memory and Language, 51, 568-585. doi:10.1016/j.jml.2004.06.010

Nickels, L., Biedermann, B., Fieder, N., \& Schiller, N. O. (2014). The lexical-syntactic representation of number. Language and Cognitive Processes. Advance online publication. doi:10.1080/23273798.23272013.23879191

Protopapas, A. (2007). CheckVocal: A program to facilitate checking the accuracy and response time of vocal responses from DMDX. Behavior Research Methods, 39, 859-862. doi:10.3758/BF03192979

R Development Core Team. (2008). R: A language and environment for statistical computing: $R$ package version 1.1-5. Retrieved from http://CRAN.R-project.org/package=lme4

Tabak, W., Schreuder, R., \& Baayen, R. H. (2010). Producing inflected verbs: A picture naming study. The Mental Lexicon, 5(1), 22-46. doi:10.1075/ml.5.1.02tab

Taft, M. (1979). Recognition of affixed words and the word frequency effect. Memory \& Cognition, 7, 263-272. doi:10.3758/BF03197599

Taft, M. (2004). Morphological decomposition and the reverse base frequency effect. Quarterly Journal of Experimental Psychology, 57, 745-765. doi:10.1080/02724980343000477

Wurm, L. H. (1997). Auditory processing of prefixed English words is both continuous and decompositional. Journal of Memory \& Language, 37, 438-461. doi:10.1006/jmla.1997.2524 
Appendix 1. List of all trials, including singular-dominant and plural-dominant words (English translations are provided in parentheses)

\begin{tabular}{|c|c|c|c|}
\hline \multicolumn{2}{|c|}{ Plural-dominant } & \multicolumn{2}{|c|}{ Singular-dominant } \\
\hline Singular & Plural & Singular & Plural \\
\hline veer [feather] & veren [feathers] & tijger [tiger] & tijgers [tigers] \\
\hline wafel [waffle] & wafels [waffles] & neus [nose] & neuzen [noses] \\
\hline wiel [wheel] & wielen [wheels] & uil $[o w l]$ & uilen $[o w l s]$ \\
\hline sok $[$ sock $]$ & sokken $[$ socks $]$ & vaas [vase] & vazen [vases] \\
\hline wolk [cloud $]$ & wolken [clouds] & helm [helmet $]$ & helmen [helmets] \\
\hline worm [worm $]$ & wormen $[$ worms $]$ & tong [tongue] & tongen [tongues] \\
\hline banaan $[$ banana $]$ & bananen [bananas] & masker $[$ mask $]$ & maskers [masks] \\
\hline haai $[$ shark $]$ & haaien [sharks] & naald [needle] & naalden [needles] \\
\hline hoef [hoof] & hoeven [hooves] & emmer [bucket] & emmers [buckets] \\
\hline oor $[$ ear $]$ & oren $[$ ears $]$ & $\operatorname{tas}[$ bag $]$ & tassen $[$ bags $]$ \\
\hline bloem [flower] & bloemen [flowers] & mes $[$ knife $]$ & messen [knives] \\
\hline ui [onion] & uien [onions] & spiegel [mirror] & spiegels [mirrors] \\
\hline wortel [carrot] & wortels [carrots] & heks [witch] & heksen [witches] \\
\hline knikker [marble] & knikkers [marbles] & leeuw [lion] & leeuwen [lions] \\
\hline vinger [finger] & vingers [fingers] & non $[$ nun $]$ & nonnen $[$ nuns] \\
\hline indiaan [indian] & indianen [indians] & klok $[$ clock $]$ & klokken $[$ clocks] \\
\hline kers $[$ cherry] & kersen [cherries] & bed $[$ bed $]$ & bedden $[$ beds $]$ \\
\hline $\operatorname{mier}[$ ant $]$ & mieren $[$ ants $]$ & bord [plate] & borden [plates] \\
\hline tomaat [tomato] & tomaten [tomatoes] & kerk [church $]$ & kerken [churches] \\
\hline vleugel [wing] & vleugels [wings] & paard [horse] & paarden [horses] \\
\hline
\end{tabular}


Appendix 2. Summary of the statistical output models specifying random and fixed effects.

RT data

Formula: $\log \mathrm{RT} \sim$ Dominance $\times$ Number $\times$ Inflectional entropy $+(1 \mid$ target $)+(1 \mid$ subject $)$

Number reference: plural

Random effects:

Groups Name Variance Std. Dev.

\begin{tabular}{llll}
\hline Subject & (Intercept) & 0.0171 & 0.1308 \\
Target & (Intercept) & 0.0102 & 0.1011 \\
Residual & & 0.0307 & 0.1751
\end{tabular}

Fixed effects:

\begin{tabular}{|c|c|c|c|c|c|}
\hline & Estimate & Std. Error & df & $t$-value & $\operatorname{Pr}(>|t|)$ \\
\hline (Intercept) & 6.904 & 0.139 & 41.1 & 49.62 & $<.001$ \\
\hline Dominance & -0.106 & 0.160 & 39.4 & -0.66 & .513 \\
\hline Number[sg] & -0.229 & 0.073 & 1316.0 & -3.15 & .002 \\
\hline Inflectional entropy & -0.053 & 0.165 & 39.4 & -0.32 & .751 \\
\hline Dominance:number[sg] & 0.179 & 0.085 & 1316.4 & 2.11 & .035 \\
\hline Dominance:inflectional entropy & 0.224 & 0.196 & 39.5 & 1.14 & .259 \\
\hline Number[sg]:inflectional entropy & 0.283 & 0.087 & 1316.4 & 3.23 & .001 \\
\hline Dominance:number[sg]:inflectional entropy & -0.364 & 0.104 & 1316.9 & -3.50 & $<.001$ \\
\hline
\end{tabular}

Error data

Formula: Accuracy $\sim$ Dominance $\times$ Number $+(1 \mid$ target $)+(1 \mid$ subject $)$

Number reference: plural

Random effects:

\begin{tabular}{|c|c|c|c|c|}
\hline Groups & Name & Variance & Std. Dev. & \\
\hline Subject & (Intercept) & 0.544 & 0.737 & \\
\hline Target & (Intercept) & 0.502 & 0.709 & \\
\hline \multicolumn{5}{|l|}{ Fixed effects: } \\
\hline & Estimate & Std. Error & z-value & $\operatorname{Pr}(>|z|)$ \\
\hline (Intercept) & 2.810 & 0.242 & 11.60 & $<.001$ \\
\hline Dominance & -0.510 & 0.338 & -1.51 & .131 \\
\hline Number[sg] & 0.522 & 0.222 & 2.36 & .018 \\
\hline Dominance:number[sg] & 1.000 & 0.442 & 2.26 & .024 \\
\hline
\end{tabular}

